\title{
Bleeding risk with invasive procedures in patients with cirrhosis and coagulopathy
}

\section{Authors:}

Nekisa Zakeri MBBS BSc MRCP ${ }^{1}$

Emmanuel A Tsochatzis MD MSc FEBTM PhD ${ }^{1}$

1. UCL Institute for Liver and Digestive Health, Royal Free Hospital and UCL, London, UK.

\section{Correspondence to:}

Emmanuel A Tsochatzis,

Sheila Sherlock Liver Unit and UCL Institute of Liver and Digestive Health,

Royal Free Hospital,

London, UK,

NW3 2QG

Tel.: +44207794500

Fax: +44 2074726226

Email: e.tsochatzis@ucl.ac.uk

Keywords: Haemostasis, transfusion, viscoelastic tests, thromboelastography, rotational thromboelastometry, anticoagulation.

Conflicts of Interest: none.

Human/Animal Rights statement: This article does not contain any studies with human or animal subjects performed by any of the authors. 


\section{ABSTRACT}

\section{Purpose of review}

Previous perceptions of cirrhosis as a hypocoagulable state have resulted in empirical blood product transfusions prior to invasive procedures. We evaluate procedure-related bleeding risks in patients with cirrhosis, assess the utility of conventional and newer global coagulation tests, and explore evidence surrounding prophylactic transfusion strategies.

\section{Recent findings}

Recent literature supports the concept of a rebalanced, albeit fragile, haemostasis equilibrium in cirrhosis, with a potential hypercoagulable tendency in stable patients. Standard coagulation tests provide a poor reflection of bleeding risks and yet are relied upon for transfusion thresholds. Consequently, a sizeable proportion of patients receive unnecessary blood products. The role of viscoelastic tests to guide transfusions requires further evaluation.

\section{Summary}

In stable cirrhotic patients procedure-related bleeding rates appear low. Prophylactic transfusion strategies based on arbitrary thresholds lack evidence of clinical benefit. There is a pressing need for point-of-care coagulation tests that represent the complex coagulopathy of cirrhosis, and well-powered randomised controlled trials to develop evidence-based preprocedure transfusion guidelines. 


\section{Introduction}

Cirrhosis has been traditionally perceived as a hypocoagulable state, prompting concern amongst clinicians over increased risks of bleeding when performing invasive procedures in this patient group [1]. As a consequence, it has remained common practice to empirically transfuse patients with impaired coagulation parameters with platelets, plasma or prohaemostatic agents to reduce bleeding risk. Recent literature has, however, challenged this notion by acknowledging the presence of a re-balanced haemostasis equilibrium in stable patients with cirrhosis [1-3]. This suggests that conventional concerns over augmented bleeding risks in cirrhosis are likely misconceived.

In this review we describe the altered haemostatic profile in patients with cirrhosis, the paradoxical pro-thrombotic tendency, and limitations of interpreting standard coagulation tests. We review recent literature assessing bleeding risks of invasive procedures in such patients, and evaluate whether empirical transfusion strategies and the use of global haemostasis assays may play any beneficial role in reducing procedure-related bleeding complications.

\section{A rebalanced haemostasis equilibrium in cirrhosis}

The liver plays a key role in haemostasis, as the primary site of synthesis for the majority of factors involved in coagulation and fibrinolysis. In addition, it produces thrombopoietin, which regulates the production of platelets from megakaryocytes. In cirrhosis, impaired protein synthesis leads to a marked reduction of both procoagulant factors (factors II, V, VII, IX, X, XI, XII) and anti-coagulant factors (anti-thrombin III, protein C and protein S) $[2,3]$. 
An exception is von Willebrand factor (VWF), derived from endothelial cells and megakaryocytes, which has increased expression due to endothelial dysfunction and reduced levels of ADAMTS13, a VWF cleaving protease. VWF promotes platelet adhesion to endothelial surfaces, platelet aggregation under high shear stress, and acts as a carrier for the procoagulant factor VIII, preventing its degradation. Increased VWF expression thereby leads to elevated factor VIII levels [2].

Thrombocytopenia occurs due to splenic sequestration from splenomegaly in portal hypertension, increased platelet destruction mediated by platelet-associated immunoglobulins, a reduced production of thrombopoietin, as well as toxic effects of ethanol on platelet production and function [3]. Unless the platelet count is severely low $\left(<50 \times 10^{9} / \mathrm{L}\right)$ thrombocytopenia does not confer increased bleeding risk, as it is offset by higher levels of VWF, mediating greater platelet adhesion $[2,4]$. In vitro studies have demonstrated normal thrombin generation in cirrhosis in the presence of endothelial-derived thrombomodulin, and adequate platelet counts $\left(>50 \times 10^{9} / \mathrm{L}\right)[5,6]$.

Hyper-fibrinolysis has been described in cirrhosis, resulting from elevated levels of tissue plasminogen activator and a deficiency of thrombin-activatable fibrinolysis inhibitor; both changes are proportional to the severity of liver disease $[2,3]$. Not all studies agree though, and it is debated whether there may be compensation from a reduction in profibrinolytic factors [2].

Table 1 demonstrates the main alterations of haemostasis in cirrhosis. Overall, in stable cirrhosis, the normal generation of thrombin as well as the concomitant acquired deficiency of both procoagulant and anticoagulant factors restores a balance in haemostasis [2, 3]. This 
rebalanced equilibrium is fragile, and can easily be tipped towards haemorrhage or thrombosis in the presence of infection, renal dysfunction or variceal haemorrhage [7]. Endogenous heparin-like effects have been demonstrated in cirrhotic patients with bacterial infections [8], explaining the role of sepsis as a contributing factor for bleeding.

Additionally, there is evidence to suggest that stable patients with cirrhosis may in fact exhibit a pro-thrombotic tendency [9], while bleeding risks appear more related to the degree of portal hypertension and collateral vessel formation rather than defective haemostasis [7]. The hypercoagulability in cirrhosis is likely to result from an increased Factor VIII to protein $\mathrm{C}$ ratio, as well as thrombomodulin resistance $[10,11]$.

\section{Standard coagulation tests as a measure of bleeding risk in cirrhosis}

Misperceptions of the bleeding risk in cirrhosis largely derive from clinicians' interpretation of standard coagulation tests, including prothrombin time (PT), international normalised ratio (INR), and activated partial thromboplastin time (APTT). However, as these conventional coagulation tests only provide a measure of procoagulant factors and are insensitive to the plasma levels of anticoagulant factors, they do not provide an accurate evaluation of the altered in-vivo haemostatic balance $[2,12]$.

Although INR is a marker of protein synthetic dysfunction and forms part of the Model for End Stage Liver Disease (MELD) prognostic score, it is a poor indicator for bleeding risk in cirrhosis. Thromboplastin calibration uses plasma obtained from patients taking vitamin $\mathrm{K}$ antagonists, and has not been validated or standardised in liver disease [13]. PT and APTT only detect the first $5 \%$ of whole thrombin formation, and are performed without adding 
thrombomodulin, therefore they do not reflect levels of activated protein $\mathrm{C}$, a principal anticoagulant which relies on thrombomodulin for activation [13]. The lack of reliability of PT or INR to assess coagulation status in cirrhosis has been recognised in the Baveno VI guidelines [14]. Furthermore, a recent meta-analysis comprising 11 guidelines and 64 studies, found only three prospective trials evaluating the use of standard plasma coagulation tests to assess coagulopathy and guide peri-operative bleeding management. The meta-analysis was not confined to patients with cirrhosis, but concluded there was no robust evidence that standard coagulation tests could provide reliable data for assessing coagulopathy, predicting bleeding risks or guiding peri-operative haemostatic therapy [15].

\section{Global haemostasis assays to predict bleeding risk in cirrhosis}

There has been considerable recent interest in the role of global haemostasis assays, in particular whole blood viscoelastic tests (VETs), as potential tools to provide more physiologically relevant insights into the coagulopathy of liver disease. Two commercially available VETs currently in clinical use include thromboelastography (TEG®, Haemonetics Corporation, Braintree, MA, United States) and rotational thromboelastometry (ROTEM $®$ Delta, TEM international GmbH, Munich, Germany) [12].

VETs are increasingly being used as point-of-care tests to guide the rapid assessment and management of coagulopathies in trauma, surgery and liver transplantation. VETs provide a dynamic assessment of haemostasis, evaluating the kinetics of the entire coagulation process from initial clot formation to final clot strength, and provide a more comprehensive reflection of the interaction between plasma, blood cells and platelets [12]. 
Literature evaluating the use of VETs does, however, show discrepancies between results. Cirrhotic patients have demonstrated normal global haemostasis as assessed by TEG, corresponding with the concept of a rebalanced haemostasis equilibrium [16, 17]. In a cohort of 273 stable cirrhotic patients, the median and mean TEG parameters were within normal limits, although the maximum amplitude (MA) decreased proportionally to the degree of thrombocytopenia [16]. An exception to this was patients with cholestatic liver diseases, who demonstrated hypercoagulability and higher clot firmness [18]. On the contrary, other recent studies have identified a hypocoagulable TEG profile in cirrhosis, indicating slower and less stable clot formation compared to healthy controls $[12,19]$. In an Italian prospective study of 261 cirrhotic patients undergoing liver transplantation, TEG values were outside the normal reference ranges in $79.3 \%$ of patients, with a trend to hypocoagulability [19]. Similarly, in a single-centre prospective study of 40 patients with cirrhosis, ROTEM demonstrated hypocoagulability despite preserved or increased endogenous thrombin potential [20].

Attempting to define specific VETs reference ranges for cirrhotic patients, rather than using current reference ranges derived from healthy individuals, may provide a more reliable estimation of coagulation status and bleeding risks [19], however is likely to prove difficult due to expected variability between patients depending on the aetiology and stage of liver disease [17].

Other limitations with the use of VETs need to be taken into consideration; platelet dysfunction is not detected, factor XIII is not adequately displayed, and the assays are insensitive to detect effects of VWF involved in the initiation of clot formation [21]. There are also concerns over standardisation of assays and reproducibility of results given interoperator variability. A UK quality assurance investigation showed a wide variation of TEG 
results between centres [22]. Consequently, while TEG is being used to guide prohaemostatic product repletion during liver transplantation, there remains insufficient evidence to support the routine use of VETs as a predictor of bleeding risk in cirrhosis, and further evaluation is required.

\section{Paradoxical thrombotic potential and role for anticoagulation in cirrhosis}

Contrary to traditional concerns for a predominant haemorrhagic potential, there is growing recognition that cirrhotic patients are at increased risk of venous thromboembolism (VTE) [9, 10, 23]. A recent systematic review and meta-analysis identified an increased risk of deep vein thrombosis ( 7 studies, $\mathrm{OR}=2.038,95 \% \mathrm{CI}=1.817-2.285)$ and pulmonary embolism (5 studies, $\mathrm{OR}=1.655,95 \% \mathrm{CI}=1.042-2.630)$ in cirrhotic patients compared to controls [23]. A higher 30-day mortality rate following VTE in cirrhotic patients was also observed [24, 25].

The one-year incidence of portal vein thrombosis (PVT) in patients with Child Pugh A or B cirrhosis was demonstrated at $4.6 \%$ [26], increasing to $16.6 \%$ in a cohort of patients with Child Pugh B or C cirrhosis [27]. The overall prevalence of PVT in cirrhosis is between 10$25 \%$, often leading to portal hypertensive complications [9]. Anticoagulation is indicated in selected cases to prevent extension of the thrombus and in some cases enables splanchnic vein recanalisation [9]. A treatment algorithm using anticoagulation with or without TIPS can improve outcomes in such patients [28].

Interestingly, additional benefits of anticoagulation in patients with cirrhosis without PVT have been demonstrated. In a single-centre non-blinded randomised controlled trial (RCT) of 70 patients with Child Pugh B or C cirrhosis, a 48-week course of enoxaparin 4000IU daily 
resulted in a lower incidence of portal vein thrombosis, with no adverse bleeding events. Secondary outcomes included fewer decompensation events and a higher survival rate compared to the control group. It was hypothesised that a potential protective effect of enoxaparin on decompensation events may be mediated through improved intestinal microcirculation, thereby reducing enterocyte damage and bacterial translocation [27]. A double-blinded multicentre RCT (CIRROXABAN) evaluating the effect of rivaroxaban on the development of portal hypertensive complications and 24-month transplant-free survival in patients with cirrhosis is currently underway (NCT02643212).

Anticoagulation may also have antifibrotic effects. Micro-vascular ischaemia has been implicated as a key factor in the progression of hepatic fibrosis and cirrhosis [29, 30]. Wanless proposed that microthrombi occlusion of branches of the portal and hepatic veins leads to sinusoidal injury, tissue ischaemia and subsequent areas of parenchymal extinction: contiguous hepatocyte apoptosis with replacement by fibrous tissue [30]. Prevention of microthrombi through prophylactic anticoagulation may counteract this. Animal models have demonstrated an improvement in hepatic fibrosis from low molecular weight heparin or warfarin therapy $[31,32]$. Interim per-protocol analysis from a UK multicentre open-label RCT (WAFT-C) of warfarin therapy in HCV patients post liver transplantation, has shown a significant reduction in fibrosis progression one-year post transplantation in the warfarin group [33]. Evaluating whether prophylactic anticoagulation could potentially reduce the progression of liver fibrosis, through inhibiting the actions of coagulation factors directly on hepatic stellate cells, represents an exciting area of future research.

\section{Bleeding rates of invasive procedures in patients with cirrhosis}


In view of the lack of standardised tests that reliably predict bleeding risk in cirrhosis, invasive procedures in these patients are often met with a degree of unease. However, since liver transplantation can feasibly be performed without requiring blood product replacement, it suggests that the altered haemostatic profile of cirrhosis does not translate to diffuse bleeding risk. Recent studies support this, showing little evidence to suggest a higher prevalence of postprocedural bleeding following invasive procedures (Table 2) [34-39].

A multicentre prospective study assessed the frequency of clinically significant bleeding in 380 cirrhotic patients with or without abnormal coagulation parameters, defined as an INR $\geq 1.5$ and/or platelet count $\leq 50 \times 10^{9} / \mathrm{L}$, undergoing both low and high risk invasive procedures [34]. No patients received pre-procedural blood product transfusions. In the low-risk procedure group, mostly entailing abdominal paracentesis, no patients had clinically significant post-procedure bleeding. In the high-risk group, including central venous cannulation or percutaneous liver biopsy, three patients in the abnormal coagulation group had clinically significant bleeding, but this did not reach statistical significance $(p=0.061)$. All three patients with clinically significant bleeding had Child Pugh C cirrhosis, elevated INR and low platelet count, and additional contributing factors of sepsis or acute kidney impairment (AKI) [34]. Similar patients with an elevated INR and low platelet count undergoing high risk procedures, but without additional sepsis or AKI, did not experience clinically significant bleeding. This study implies that invasive procedures can be safely carried out in stable cirrhotic patients without empirical transfusion of pro-haemostatic products; with no pronounced increased bleeding risks in cases of thrombocytopenia and/or prolonged INR. 
Additionally, in an Italian case series of 363 cirrhotic patients undergoing a total of 852 invasive procedures, post procedural bleeding was infrequent, occurring in one in every 36 patients, was more common in patients who underwent repeat procedures, and was unrelated to the platelet count, INR, Child Pugh grade, MELD score or risk category of invasive procedures. In fact, none of the ten patients with the most deranged coagulation parameters experienced post-procedural bleeding, including several cases of uncorrected pre-procedure platelet counts of less than $20 \times 10^{9} / \mathrm{L}$ or INR values above 2 [37].

Other studies have evaluated bleeding rates in cirrhotic patients according to specific procedure types. In a retrospective USA study of 240 patients undergoing cardiac catheterisation, no procedure-related bleeding events or major vascular complications occurred. INR values ranged from 0.93 to 2.35 . 17 patients received fresh frozen plasma (FFP) pre-procedure, in most cases without a significant reduction in INR. No correlation was found between post-procedure changes in haemoglobin and INR values [35].

A small retrospective Korean study of 30 patients with predominantly Child Pugh grade A or B cirrhosis undergoing colonoscopy with polypectomy, found a low rate of immediate postpolypectomy bleeding. The mean prothrombin time of patients was 1.3 , and the mean platelet count was $137 \times 10^{9} / \mathrm{L}$. Only $2 / 66$ polyp removals resulted in mild oozing, which was controlled by the application of haemoclips, with no delayed post-polypectomy bleeding [36].

A large retrospective single centre study in USA analysing complications from 3357 percutaneous liver biopsies performed with Klatskin needles across a 36-year period, identified a low total bleeding rate of $0.6 \%$ (21/3357 biopsies) [38]. Patients with bleeding complications had higher total bilirubin and alkaline phosphatase levels, and lower albumin 
levels. The median pre-biopsy platelet count, PT and APTT did not differ between patients that did or did not experience bleeding complications, however multivariate backward stepwise logistic regression identified a combination of APTT $>35$ s and platelet count $\leq 100$ $\mathrm{x} 10^{9} / \mathrm{L}$, as predictors of bleeding risk. An elevated PT $>13.5 \mathrm{~s}$ was not significantly associated. Three patients $(0.09 \%$ of the total cohort $)$ died from massive intraperitoneal haemorrhage; all had been acutely unwell prior to the procedure. Individual coagulation parameters were not described. One patient had decompensated hepatitis C virus (HCV) cirrhosis and a focal liver lesion, the second had decompensated cirrhosis with an underlying glycogen storage disorder, and the third had severe graft-versus-host disease with hepatic involvement following a previous bone marrow transplant. Arterial embolisation and surgical intervention were attempted but unsuccessful [38].

Bleeding complications following percutaneous liver biopsies remains overall though a rare event. A total bleeding rate of $0.6 \%$ (16/2740 procedures) was identified in a cohort of patients with HCV and advanced fibrosis or cirrhosis enrolled in the HALT-C trial. Bleeding risk was higher in patients with a platelet count of less than $60 \times 10^{9} / \mathrm{L}$, while none of the eight patients with an INR above 1.5 experienced bleeding complications [39].

In our centre, percutaneous liver biopsies require a platelet count of above 50x10 $/ \mathrm{L}$ and INR less than 1.5; outside these parameters, transjugular liver biopsies are preferred, without necessitating prophylactic transfusions. For radiofrequency ablation of hepatocellular carcinoma, we require a platelet count of above $70 \times 10^{9} / \mathrm{L}$ and INR below 1.8 . We do not routinely correct deranged coagulation parameters for abdominal paracentesis, banding of oesophageal varices or central venous cannulation in stable cirrhotic patients; experienced operators are recommended to minimise procedural bleeding risks. 
Our practice remains the same for patients with compensated and decompensated cirrhosis, provided there is no active bleeding. Invasive procedures in cirrhotic patients with renal failure, sepsis or disseminated intravascular coagulation, however, pose greater uncertainty as the fragile haemostasis equilibrium is disrupted. There is an apparent paucity of literature in this area, thus the best approach to procedure management in these patients has not been established. Acknowledged limitations of standard coagulation tests also provides additional challenges. In cirrhotic patients with renal failure, we opt for more conservative platelet thresholds due to anticipated platelet dysfunction, transfusing a single pool of platelets for a pre-procedure platelet count of less than $80 \times 10^{9} / \mathrm{L}$. In patients with sepsis our standard practice is unchanged, except in cases of disseminated intravascular coagulation, where due to considerably augmented bleeding risks we aim to correct deranged coagulation parameters prior to invasive procedures to achieve a target INR of less than 1.5 and platelet count above $50 \times 10^{9} / \mathrm{L}$.

\section{Empirical transfusion strategies prior to invasive procedures}

In a retrospective study of 1595 cirrhotic patients across 11 tertiary-care hospitals in China, $14.8 \%$ of patients received one or more plasma transfusions during their hospital admission. The majority of plasma transfusions $(73.3 \%)$ were administered to patients without signs of bleeding, and in $70.4 \%$ of cases there were no planned invasive procedures [40].

There is a recognisable lack of well-powered randomised controlled trials to provide evidence based pre-procedure transfusion guidelines. Recently updated recommendations from the British Committee for Standards in Haematology advise platelet transfusion thresholds 
according to procedure type; less than $50 \times 10^{9} / \mathrm{L}$ for percutaneous liver biopsy or major surgery, less than $20 \times 10^{9} / \mathrm{L}$ for central venous line insertion, and no routine platelet transfusion for bone marrow aspiration or trephine biopsy. No specific recommendations for cirrhotic patients are defined [41].

Traditionally patients with cirrhosis have been empirically transfused with plasma or prohaemostatic agents prior to invasive procedures in an attempt to reduce bleeding complications. Evidence supporting this practice is however lacking, and a sizeable proportion of inpatients with cirrhosis end up receiving unnecessary transfusions. An INR above 1.5 and a haemoglobin level less than $8 \mathrm{~g} / \mathrm{dL}$ represent arbitrary thresholds used to guide pre-procedure prophylactic FFP and red blood cell (RBC) transfusions respectively, although this practice remains essentially habit driven rather than evidence-based [15]. UK [42] and Baveno VI [14] guidelines for the management of variceal bleeding in cirrhotic patients recommend RBC transfusion to a target haemoglobin between $7 \mathrm{~g} / \mathrm{dL}$ and $8 \mathrm{~g} / \mathrm{dL}$, with consideration for individual patient factors and haemodynamic stability.

A UK nationwide prospective audit of 1313 consecutive patients with cirrhosis across 85 hospitals, found that $30 \%$ of patients were transfused at least one blood product during admission. In $61 \%$ of cases this was for treatment of bleeding, and in $39 \%$ for prophylaxis. There were no planned invasive procedures in $61 \%$ of patients that were prophylactically transfused. In the bleeding group, $25 \%$ of patients received $\mathrm{RBC}$ transfusion for a haemoglobin $>8 \mathrm{~g} / \mathrm{dL}, 40 \%$ received FFP for an INR $<1.5$, and $46 \%$ received platelets for a pre-transfusion platelet count $\geq 50 \times 10^{9} / \mathrm{L}$. In the prophylaxis group, in the absence of bleeding, $29 \%$ of patients received FFP, $20 \%$ received RBC for a haemoglobin $>8 \mathrm{~g} / \mathrm{dl}$, and $36 \%$ received platelets prior to procedures for a platelet count $\geq 50 \times 10^{9} / \mathrm{L}$ [43]. The 
widespread practice of unnecessary transfusions in this patient population carries a significant financial impact and increases demands on an already scarce resource.

A single-centre observational study evaluating hospital blood product use, showed that patients with liver disease disproportionately received $32.4 \%$ of all FFP administered, the majority for pre-procedure prophylaxis [44]. However, no clear benefit to this practice has been demonstrated. In a case series of 363 cirrhotic patients, the transfusion of platelets or FFP prior to invasive procedures led to only a modest improvement in platelet count or INR, without any evidence for clinical benefit, and in the majority of cases not achieving normalisation of coagulation parameters. In fact, no bleeding events occurred in all 89 patients with platelet counts below $50 \times 10^{9} / \mathrm{L}$, challenging the widely-employed platelet transfusion threshold [37].

As well as increased healthcare costs from the unnecessary transfusion of blood products, the risks of inflicting harm need to be considered. Although rare, transfusion related adverse reactions after FFP have been demonstrated, including transfusion-related acute lung injury, bacterial infections and volume overload [45]. Over-transfusion of RBC in the context of variceal bleeding is associated with worse outcomes, likely due to a rise in portal venous pressure. A RCT of 921 patients with severe acute upper gastrointestinal bleeding showed that a restrictive transfusion strategy (transfusion for a haemoglobin below $7 \mathrm{~g} / \mathrm{dL}$ ) in cirrhotic patients was associated with reduced rates of re-bleeding and fewer adverse events compared to a liberal transfusion strategy (transfusion for a haemoglobin below 9g/dL). Subgroup analysis further demonstrated a lower mortality rate with restrictive transfusion for patients with Child Pugh A or B cirrhosis [46]. 
The practice of transfusing platelets pre-procedure remains arbitrary, as neither a threshold value to trigger transfusion nor an effective target platelet count to aim for have been established [2]. In a cohort of 26 thrombocytopenic patients with cirrhosis (platelet count $\left.<50 \times 10^{9} / \mathrm{L}\right)$ undergoing variceal ligation, the transfusion of a single adult platelet pool was barely able to increase the platelet count. There was no significant effect on thrombin generation, and while a marginal improvement in thromboelastography occurred, no patients reached normal values. Whether more vigorous transfusion strategies aimed at achieving greater increases in platelet levels may normalise global haemostasis results and confer true prognostic benefit remains to be elucidated [5].

Initial studies evaluating the use of thrombopoietin receptor agonists prior to elective invasive procedures in patients with cirrhosis, demonstrate a rise in platelet counts thus reducing platelet transfusion requirements, but with no established reduction in bleeding events (5357). In a single-centre double-blinded RCT of 292 cirrhotic patients (platelet count $<50 \times 10^{9} / \mathrm{L}$ ), avoidance of platelet transfusions prior to elective procedures was achieved in $72 \%$ of patients who received 14-days of eltrombopag, compared with $19 \%$ of patients in the placebo group $(\mathrm{p}<0.001)$. Higher pre-procedure platelet counts achieved by the treatment group did not improve bleeding outcomes; however, the risk of thrombotic events increased when the platelet count exceeded $200 \times 10^{9} / \mathrm{L}$. Thrombosis of the portal venous system was observed in six patients in the eltrombopag group compared with one patient in the placebo group, resulting in early termination of the study (54). Therefore, eltrombopag is not currently recommended as an alternative to platelet transfusions in cirrhotic patients with thrombocytopenia undergoing invasive procedures. Other thrombopoietin receptor agonists, romiplostim and avatrombopag, show efficacy in improving platelet counts but detailed data regarding adverse events are not provided and larger scale RCTs are required (55-57). 
Coagulation factor concentrates, such as recombinant factor VIIa and prothrombin complex concentrate, have also been suggested as potential alternatives to reduce bleeding risk [47, 48]. Case reports for the prophylactic use of factor VIIa prior to invasive procedures in stable cirrhotic patients with a prolonged INR have been described [48], however strong evidence for its efficacy is lacking, and concerns remain over its cost effectiveness and pro-thrombotic potential. A multicentre RCT found no significant effect of recombinant factor VIIa therapy on controlling 24-hour bleeding, preventing clinically significant re-bleeding or improving day five mortality following variceal bleeding in patients with advanced cirrhosis. No overall difference in adverse events was demonstrated compared to placebo, though arterial thromboembolic events were only observed in the factor VIIa treatment group [49]. RCTs are underway to assess the impact of pre-operative administration of prothrombin complex concentrate on perioperative blood loss and transfusion requirements during liver transplantation [47].

\section{VETs guided pre-procedure transfusions}

The first clinical use of TEG in patients with liver disease was to guide the administration of pro-haemostatic products in patients undergoing liver transplantation [18]. However, the efficacy of TEG guided transfusion strategies in reducing bleeding risks from other invasive procedures remains under evaluation. Moreover, the proposed TEG cut-off values for transfusion are subject to great variability.

In a prospective trial of 28 patients undergoing liver transplantation, patients monitored intraoperatively by TEG received significantly less FFP compared to patients monitored by 
standard coagulation tests (mean 12.8 units vs. 21.5 units), with no difference in three-year survival [50]. Similarly, a significant reduction in RBC, FFP and platelet transfusions with ROTEM-guided haemostasis management was observed in a prospective study of 200 patients undergoing liver transplantation. The incidence of blood product free transplantations increased from $5 \%$ to $24 \%$ [51].

A single-centre open label RCT compared a TEG-guided pre-procedure transfusion protocol against standard of care in 60 cirrhotic patients (60\% Child Pugh C) with significant coagulopathy, defined as an INR $>1.8$ and/or a platelet count $<50 \times 10^{9} / \mathrm{L}$. Abdominal paracentesis was the most commonly performed procedure, and endoscopic variceal banding was the most common high-risk procedure. All patients in the control group received blood products, compared to five patients in the TEG group $(100 \%$ vs. $16.7 \%, \mathrm{p}<0.0001)$. In both groups transfusion occurred more commonly in low-risk rather than high-risk procedures. Post-procedure bleeding was experienced by only one patient in the control group, with a pretransfusion INR of 2.03 and platelet count of $111 \times 10^{9} / \mathrm{L}$, who underwent large volume paracentesis and had received prior FFP. No difference in 90-day survival was observed between the two groups [52]. A very low procedure bleeding risk (1.7\%) was thus demonstrated, even in predominantly Child Pugh $\mathrm{C}$ patients. The bleeding risk was not related to coagulopathy or the use of transfusion products. A TEG-guided transfusion protocol resulted in $83.3 \%$ fewer blood products being used; moreover, the TEG thresholds used for transfusion (FFP if reaction time was $>40 \mathrm{~min}$ and/or platelets if maximum amplitude was $<30 \mathrm{~mm}$ ) may be conservative and could be re-evaluated to further reduce unnecessary blood product use [52]. Additional RCTs are needed to validate these findings.

\section{Conclusions}


Cirrhosis is no longer considered to be a hypocoagulable state; in-vitro studies demonstrate the existence of a re-balanced haemostasis equilibrium, but this can easily be disturbed. In fact, patients with cirrhosis paradoxically often exhibit more of a pro-thrombotic tendency.

The risks of bleeding from invasive procedures in stable cirrhotic patients appears to be low, even in the presence of abnormal coagulation parameters. Empirical pre-procedure transfusion of blood products remains unnecessarily high due to arbitrary transfusion thresholds being relied upon, despite insufficient evidence for any clinical benefit. Conventional coagulation tests are limited in their ability to predict bleeding risk in cirrhosis and a growing body of evidence now questions their efficacy in guiding transfusion decisions.

There is a pressing need for more reliable and comprehensive coagulation tests that accurately represent the complex coagulopathy of cirrhosis and help guide the management of thrombotic or haemorrhagic complications. The use of VETs at present lacks sufficient evidence for routine clinical use but warrants further evaluation. In the meantime, given limitations in accurately predicting bleeding risks, decisions to proceed with invasive procedures in patients with cirrhosis should be made after careful consideration of risks and benefits. 


\section{References:}

1. Tsochatzis, E.A., J. Bosch, and A.K. Burroughs, Liver cirrhosis. Lancet, 2014. 383(9930): p. 1749-61.

2. * Tripodi, A., Hemostasis abnormalities in cirrhosis. Curr Opin Hematol, 2015. 22(5): p. 406-12. Excellent review discussing the rebalanced haemostasis in cirrhosis.

3. Mucino-Bermejo, J., et al., Coagulation abnormalities in the cirrhotic patient. Ann Hepatol, 2013. 12(5): p. 713-24.

4. Lisman, T., et al., Elevated levels of von Willebrand Factor in cirrhosis support platelet adhesion despite reduced functional capacity. Hepatology, 2006. 44(1): p. 5361.

5. Tripodi, A., et al., Global hemostasis tests in patients with cirrhosis before and after prophylactic platelet transfusion. Liver Int, 2013. 33(3): p. 362-7.

6. Tripodi, A., et al., Evidence of normal thrombin generation in cirrhosis despite abnormal conventional coagulation tests. Hepatology, 2005. 41(3): p. 553-8.

7. Fatourou, E.M. and E.A. Tsochatzis, Transfusion strategies in patients with cirrhosis: less is more. Liver Int, 2016. 36(4): p. 503-4.

8. Montalto, P., et al., Bacterial infection in cirrhosis impairs coagulation by a heparin effect: a prospective study. J Hepatol, 2002. 37(4): p. 463-70.

9. Tsochatzis, E.A., et al., Systematic review: portal vein thrombosis in cirrhosis. Aliment Pharmacol Ther, 2010. 31(3): p. 366-74. 
10. Tripodi, A., et al., An imbalance of pro- vs anti-coagulation factors in plasma from patients with cirrhosis. Gastroenterology, 2009. 137(6): p. 2105-11.

11. Tripodi, A., et al., Evidence that low protein $C$ contributes to the procoagulant imbalance in cirrhosis. J Hepatol, 2013. 59(2): p. 265-70.

12. Shin, K.H., et al., Thromboelastographic Evaluation of Coagulation in Patients With Liver Disease. Ann Lab Med, 2017. 37(3): p. 204-212.

13. Buresi, M., R. Hull, and C.S. Coffin, Venous thromboembolism in cirrhosis: a review of the literature. Can J Gastroenterol, 2012. 26(12): p. 905-8.

14. de Franchis, R., Expanding consensus in portal hypertension: Report of the Baveno VI Consensus Workshop: Stratifying risk and individualizing care for portal hypertension. J Hepatol, 2015. 63(3): p. 743-52.

15. Haas, T., et al., Usefulness of standard plasma coagulation tests in the management of perioperative coagulopathic bleeding: is there any evidence? $\mathrm{Br} \mathrm{J}$ Anaesth, 2015. 114(2): p. 217-24.

16. Lloyd-Donald, P., et al., Coagulation in acutely ill patients with severe chronic liver disease: Insights from thromboelastography. J Crit Care, 2017. 38: p. 215-224.

17. Mallett, S.V., Clinical Utility of Viscoelastic Tests of Coagulation (TEG/ROTEM) in Patients with Liver Disease and during Liver Transplantation. Semin Thromb Hemost, 2015. 41(5): p. 527-37.

18. Stravitz, R.T., Potential applications of thromboelastography in patients with acute and chronic liver disease. Gastroenterol Hepatol (N Y), 2012. 8(8): p. 513-20.

19. De Pietri, L., et al., Thromboelastographic reference ranges for a cirrhotic patient population undergoing liver transplantation. World J Transplant, 2016. 6(3): p. 58393. 
20. Lentschener, C., et al., Assessment of haemostasis in patients with cirrhosis: Relevance of the ROTEM tests?: A prospective, cross-sectional study. Eur J Anaesthesiol, 2016. 33(2): p. 126-33.

21. Lance, M.D., A general review of major global coagulation assays: thrombelastography, thrombin generation test and clot waveform analysis. Thromb J, 2015. 13: p. 1.

22. Kitchen, D.P., et al., Quality assurance and quality control of thrombelastography and rotational Thromboelastometry: the UK NEQAS for blood coagulation experience. Semin Thromb Hemost, 2010. 36(7): p. 757-63.

23. Ambrosino, P., et al., The risk of venous thromboembolism in patients with cirrhosis. A systematic review and meta-analysis. Thromb Haemost, 2017. 117(1): p. 139-148.

24. $\mathrm{Wu}, \mathrm{H}$. and G.C. Nguyen, Liver cirrhosis is associated with venous thromboembolism among hospitalized patients in a nationwide US study. Clin Gastroenterol Hepatol, 2010. 8(9): p. 800-5.

25. Sogaard, K.K., et al., Cirrhosis is Associated with an Increased 30-Day Mortality After Venous Thromboembolism. Clin Transl Gastroenterol, 2015. 6: p. e97.

26. Nery, F., et al., Causes and consequences of portal vein thrombosis in 1,243 patients with cirrhosis: results of a longitudinal study. Hepatology, 2015. 61(2): p. 660-7.

27. * Villa, E., et al., Enoxaparin prevents portal vein thrombosis and liver decompensation in patients with advanced cirrhosis. Gastroenterology, 2012. 143(5): p. 1253-60.e1-4. Randomised controlled trial demonstrating improved outcomes in patients with Child Pugh B or C cirrhosis treated with prophylactic enoxaparin. 
28. Senzolo, M., et al., Prospective evaluation of anticoagulation and transjugular intrahepatic portosystemic shunt for the management of portal vein thrombosis in cirrhosis. Liver Int, 2012. 32(6): p. 919-27.

29. Anstee, Q.M., A. Dhar, and M.R. Thursz, The role of hypercoagulability in liver fibrogenesis. Clin Res Hepatol Gastroenterol, 2011. 35(8-9): p. 526-33.

30. Wanless, I.R., et al., Hepatic and portal vein thrombosis in cirrhosis: possible role in development of parenchymal extinction and portal hypertension. Hepatology, 1995. 21(5): p. 1238-47.

31. Abe, W., et al., Low molecular weight heparin prevents hepatic fibrogenesis caused by carbon tetrachloride in the rat. J Hepatol, 2007. 46(2): p. 286-94.

32. Anstee, Q.M., et al., Coagulation status modulates murine hepatic fibrogenesis: implications for the development of novel therapies. J Thromb Haemost, 2008. 6(8): p. 1336-43.

33. Dhar, A., Tsochatzis, E, Brown, R et al., Warfarin anticoagulation for liver fibrosis in patients transplanted for hepatitis C (WAFT-C): results at one year. J Hepatol, 2015.

\section{2:S268}

34. *Shah, A., et al., Coagulopathy in cirrhosis: A prospective study to correlate conventional tests of coagulation and bleeding following invasive procedures in cirrhotics. Indian J Gastroenterol, 2015. 34(5): p. 359-64. Prospective study demonstrating a low bleeding rate in cirrhotic patients undergoing invasive procedures without correction of abnormal coagulation parameters.

35. Townsend, J.C., et al., Usefulness of international normalized ratio to predict bleeding complications in patients with end-stage liver disease who undergo cardiac catheterization. Am J Cardiol, 2012. 110(7): p. 1062-5. 
36. Jeon, J.W., et al., The risk of postpolypectomy bleeding during colonoscopy in patients with early liver cirrhosis. Surg Endosc, 2012. 26(11): p. 3258-63.

37. ** Napolitano, G., et al., Bleeding after invasive procedures is rare and unpredicted by platelet counts in cirrhotic patients with thrombocytopenia. Eur J Intern Med, 2017. 38: p. 79-82. Case series of invasive procedures in cirrhotic patients demonstrating a low bleeding risk, unrelated to platelet count or coagulation parameters, and a lack of clinical benefit for pre-procedure transfusions of platelets or fresh frozen plasma.

38. Takyar, V., et al., Complications of percutaneous liver biopsy with Klatskin needles: a 36-year single-centre experience. Aliment Pharmacol Ther, 2017. 45(5): p. 744-753.

39. Seeff, L.B., et al., Complication rate of percutaneous liver biopsies among persons with advanced chronic liver disease in the HALT-C trial. Clin Gastroenterol Hepatol, 2010. 8(10): p. 877-83.

40. Lu, Y., et al., Plasma Transfusion in Patients With Cirrhosis in China: A Retrospective Multicenter Cohort Study. Transfus Med Rev, 2017. 31(2): p. 107-112.

41. Estcourt, L.J., et al., Guidelines for the use of platelet transfusions. Br J Haematol, 2017. 176(3): p. 365-394.

42. Tripathi, D., et al., U.K. guidelines on the management of variceal haemorrhage in cirrhotic patients. Gut, 2015. 64(11): p. 1680-704.

43. * Desborough, M.J., et al., Patterns of blood component use in cirrhosis: a nationwide study. Liver Int, 2016. 36(4): p. 522-9. UK nationwide audit highlighting a widespread practice of unnecessary blood product transfusions in patients with cirrhosis admitted to hospital. 
44. Shah, N.L., P.G. Northup, and S.H. Caldwell, A clinical survey of bleeding, thrombosis, and blood product use in decompensated cirrhosis patients. Ann Hepatol, 2012. 11(5): p. 686-90.

45. Delaney, M., et al., Transfusion reactions: prevention, diagnosis, and treatment. Lancet, 2016. 388(10061): p. 2825-2836.

46. ** Villanueva, C., et al., Transfusion strategies for acute upper gastrointestinal bleeding. N Engl J Med, 2013. 368(1): p. 11-21. Landmark randomised controlled trial demonstrating better outcomes with a restrictive transfusion strategy in cirrhotic patients presenting with acute upper gastrointestinal bleeding.

47. Arshad, F., et al., Prothrombin complex concentrate in the reduction of blood loss during orthotopic liver transplantation: PROTON-trial. BMC Surg, 2013. 13: p. 22.

48. Tsochatzis, E., et al., Prophylactic and therapeutic use of recombinant activated factor VII in patients with cirrhosis and coagulation impairment. Dig Liver Dis, 2007. 39(5): p. 490-4.

49. Bosch, J., et al., Recombinant factor VIIa for variceal bleeding in patients with advanced cirrhosis: A randomized, controlled trial. Hepatology, 2008. 47(5): p. 160414.

50. Wang, S.C., et al., Thromboelastography-guided transfusion decreases intraoperative blood transfusion during orthotopic liver transplantation: randomized clinical trial. Transplant Proc, 2010. 42(7): p. 2590-3.

51. Leon-Justel, A., et al., Point-of-care haemostasis monitoring during liver transplantation reduces transfusion requirements and improves patient outcome. Clin Chim Acta, 2015. 446: p. 277-83.

52. ** De Pietri, L., et al., Thrombelastography-guided blood product use before invasive procedures in cirrhosis with severe coagulopathy: A randomized, controlled trial. 
Hepatology, 2016. 63(2): p. 566-73. Randomised controlled trial of cirrhotic patients undergoing invasive procedures, showing benefits of TEG-guided transfusion protocols in reducing blod product use.

53. Qureshi et al The Use of Thrombopoietin Receptor Agonists for Correction of Thrombocytopenia prior to Elective Procedures in Chronic Liver Diseases: Review of Current Evidence

54. Afdhal N. H., Giannini E. G., Tayyab G., et al. Eltrombopag before procedures in patients with cirrhosis and thrombocytopenia. The New England Journal of Medicine.

2012;367(8):716-724.

55. Terrault N. A., Hassanein T., Howell C. D., et al. Phase II study of avatrombopag in thrombocytopenic patients with cirrhosis undergoing an elective procedure. Journal of Hepatology. 2014;61(6):1253-1259.

56. Moussa M. M., Mowafy N. Preoperative use of romiplostim in thrombocytopenic patients with chronic hepatitis C and liver cirrhosis. Journal of Gastroenterology and Hepatology.

$2013 ; 28(2): 335-341$

57. Basu P., Nair T., Farhat S., Shah N., Jafri M., Fousin S. Single use of romiplostim thrombopoietin analogue in severe thrombocytopenia for outpatient percutaneous liver biopsy in patients with chronic liver disease — a randomized double blinded prospective trial. 
Table 1

Alterations of haemostasis in cirrhosis

\begin{tabular}{lll}
\hline & Pro-haemostatic mechanisms & Anti-haemostatic mechanisms \\
Primary & Increased VWF & Thrombocytopenia \\
\hline Coagulation & Reduced ADAMTS-13 & \\
& Increased Factor VIII & Reduced production of \\
& Reduced production of & procoagulant factors II, V, VII, \\
& anticoagulants: anti-thrombin & IX, X, XI, XII \\
& III, protein C, protein S & \\
\hline Fibrinolysis & Low levels of plasminogen & Increased tPA \\
& Increased PAI-1 & Reduced TAFI \\
& & Reduced a2-antiplasmin \\
\end{tabular}

$V W F$, von Willebrand factor; ADAMTS-13, a disintegrin and metalloproteinase with a thrombospondin type 1 motif, member 13 (VWF cleaving protease); PAI-1, plasminogen activator inhibitor-1; $t P A$, tissue plasminogen activator; $T A F I$, thrombin-activatable fibrinolysis inhibitor. 


\section{Table 2}

Bleeding rates of invasive procedures in patients with cirrhosis

\begin{tabular}{|c|c|c|c|c|c|}
\hline Authors & Study design & $\begin{array}{l}\text { Number of } \\
\text { cirrhotic } \\
\text { patients } \\
\text { (\% of Child } \\
\text { Pugh grade } \\
\text { A/B/C) }\end{array}$ & Procedure types & $\begin{array}{l}\text { Clinically } \\
\text { significant } \\
\text { bleeding } \\
\text { complications } \\
(\%)\end{array}$ & $\begin{array}{l}\text { Associations with } \\
\text { bleeding complications }\end{array}$ \\
\hline $\begin{array}{l}\text { Napolitano } \\
\text { et al. }(2017) \\
\text { [37] }\end{array}$ & $\begin{array}{l}\text { Prospective } \\
\text { single centre }\end{array}$ & $\begin{array}{l}363 \\
(34 \% / 43 \% / 23 \%)\end{array}$ & $\begin{array}{l}\text { Low risk: } \\
\text { endoscopic } \\
\text { procedures, large } \\
\text { volume } \\
\text { paracentesis, dental } \\
\text { extraction } \\
\text { Intermediate risk: } \\
\text { Percutaneous } \\
\text { needle biopsy/HCC } \\
\text { ablation, } \\
\text { laparoscopic } \\
\text { procedures }\end{array}$ & $\begin{array}{l}\text { 10/363 patients } \\
(2.75 \%)\end{array}$ & $\begin{array}{l}\text { Child Pugh A/B/C: } 1 / 5 / 4 \\
\text { PLT/INR unrelated to } \\
\text { bleeding risk } \\
\text { PLT > 50: } n=10, \\
\text { PLT } \leq 50: n=0 \\
4 \text { transfused PLT } \\
\text { INR } \leq 1.3, n=5, \\
\text { INR }>1.3, n=5 \\
\text { INR range } 1.10-1.85 \\
3 \text { transfused FFP }\end{array}$ \\
\hline
\end{tabular}




\begin{tabular}{|c|c|c|c|c|c|}
\hline & & & $\begin{array}{l}\text { High risk: Vascular } \\
\text { catheterisation, } \\
\text { open incision in } \\
\text { body cavity/tissue } \\
\text { space }\end{array}$ & & $\begin{array}{l}3 \text { low risk/3 intermediate } \\
\text { risk/4 high risk } \\
\text { procedures }\end{array}$ \\
\hline $\begin{array}{l}\text { Takyar et } \\
\text { al. (2017) } \\
{[38]}\end{array}$ & $\begin{array}{l}\text { Retrospective } \\
\text { single centre, } \\
\text { 36-year } \\
\text { period }\end{array}$ & $\begin{array}{l}341 / 3357 \\
\text { confirmed } \\
\text { cirrhotic } \\
\text { (Child Pugh } \\
\text { grade not } \\
\text { specified) }\end{array}$ & $\begin{array}{l}\text { Percutaneous liver } \\
\text { biopsy with } \\
\text { Klatskin needle }\end{array}$ & $\begin{array}{l}21 / 3357 \\
\text { procedures } \\
(0.63 \%)\end{array}$ & $\begin{array}{l}\text { Bleeding associated with: } \\
\text { higher ALP, higher } \\
\text { bilirubin, lower albumin, } \\
\text { increased biopsy size } \\
\text { APTT >35s and platelet } \\
\text { count } \leq 100 \mathrm{~K} / \mu \mathrm{L} \\
\text { predictors of bleeding } \\
\text { risk (multivariate } \\
\text { backward stepwise } \\
\text { logistic regression) } \\
3 \text { died: intraperitoneal } \\
\text { haemorrhage }\end{array}$ \\
\hline $\begin{array}{l}\text { Shah } \text { et al. } \\
\text { (2015) [34] }\end{array}$ & $\begin{array}{l}\text { Prospective } \\
\text { multicentre }\end{array}$ & $\begin{array}{l}380 \\
(39 \% / 40 \% / 21 \%) \\
128 \text { with } \\
\text { coagulopathy: }\end{array}$ & $\begin{array}{l}\text { Low risk: } \\
\text { abdominal } \\
\text { paracentesis, } \\
\text { endoscopic band } \\
\text { ligation, glue }\end{array}$ & $\begin{array}{l}\text { 3/380 patients } \\
(0.79 \%)\end{array}$ & $\begin{array}{l}\text { Child Pugh A/B/C: 0/0/3 } \\
\text { All } 3 \text { had INR } \geq 1.5 \text { and } \\
\text { platelet } \leq 50,000 / \text { cum, } \\
\text { and contributing factors }\end{array}$ \\
\hline
\end{tabular}




\begin{tabular}{|c|c|c|c|c|c|}
\hline & & $\begin{array}{l}(\text { INR } \geq 1.5+/- \\
\text { platelet } \\
\leq 50,000 / \text { cum }) \\
252 \text { : No } \\
\text { coagulopathy }\end{array}$ & $\begin{array}{l}\text { injection, } \\
\text { sclerotherapy } \\
\text { High risk: major } \\
\text { surgery, central } \\
\text { vein cannulation, } \\
\text { percutaneous liver } \\
\text { biopsy, } \\
\text { chemoembolization } \\
\text {, endoscopic } \\
\text { polypectomy }\end{array}$ & & $\begin{array}{l}\text { of sepsis or AKI } \\
3 \text { high risk } / 0 \text { low risk } \\
\text { procedures ( } \mathrm{p}=0.061 \text { ) }\end{array}$ \\
\hline $\begin{array}{l}\text { Townsend } \\
\text { et al. (2012) } \\
\text { [35] }\end{array}$ & $\begin{array}{l}\text { Retrospective } \\
\text { single centre }\end{array}$ & $\begin{array}{l}240 \\
\text { (Child Pugh } \\
\text { grade not } \\
\text { specified) }\end{array}$ & $\begin{array}{l}\text { Cardiac } \\
\text { catheterisation }\end{array}$ & $\begin{array}{l}0 / 240 \text { patients } \\
(0 \%)\end{array}$ & $\begin{array}{l}\text { No major bleeding events } \\
\text { INR range } 0.93-2.35 \\
\text { (17 patients received } \\
\text { FFP, } 6 \text { received PLT, } 6 \\
\text { received RBC } \\
\text { transfusion) }\end{array}$ \\
\hline $\begin{array}{l}\text { Jeon et al. } \\
\text { (2012) [36] }\end{array}$ & $\begin{array}{l}\text { Retrospective } \\
\text { single centre }\end{array}$ & $\begin{array}{l}30 \\
(70 \% / 27 \% / 3 \%)\end{array}$ & $\begin{array}{l}\text { Colonoscopy with } \\
\text { polypectomy }\end{array}$ & \begin{tabular}{|l} 
0/66 \\
procedures \\
major bleeding \\
2/66 mild \\
bleeding (3\%)
\end{tabular} & $\begin{array}{l}\text { Polyp size and } \\
\text { morphology associated } \\
\text { with immediate post- } \\
\text { polypectomy bleeding } \\
\text { No association with } \\
\text { platelet count, INR, }\end{array}$ \\
\hline
\end{tabular}




\begin{tabular}{|l|l|l|l|l|l|}
\hline Seeff et al. & Retrospective & Biopsy total: & Percutaneous liver & $16 / 2740$ & Child Pugh grade \\
(2010) [39] & multicentre & 2740 in HCV & biopsy & procedures & with platelet count \\
& advanced & & $(0.58 \%)$ & $<60,000 / \mathrm{mm}^{3}, \mathrm{INR}^{2} \geq 1.3$. \\
& & Pugh A cirrhosis & & & But no patients with \\
& & & & & INR $>1.5$ had bleeding \\
\end{tabular}

PLT, Platelets; INR, International Normalised Ratio; ALP, Alkaline Phosphatase; AKI, Acute Kidney Injury; $F F P$, fresh frozen plasma; $R B C$, red blood cell; $A P T T$, activated partial thromboplastin time. 